\title{
Preconception care and contraceptive use among Australian women with diabetes mellitus
}

Emily J Hibbert, Santhi Chalasani, Pinar Kozan, Rickie Myszka, Kris EJ Park, Kirsten I Black

\section{Background and objective Effective contraception is important for pregnancy planning and reducing adverse pregnancy outcomes in women with diabetes mellitus (DM). The aim of this study was to explore preconception care practices and contraception use among women with DM.}

\section{Methods}

The study used a cross-sectional structured questionnaire to survey women with DM aged 16-49 years in Nepean Blue Mountains Local Health District (NBMLHD), a Western Sydney tertiary referral centre.

\section{Results}

A total of 107 of 215 (49.7\%) women completed the questionnaire. While $80.4 \%$ were aware of DM-related pregnancy risks, preconception advice was reported by only $46.8 \%$ of the 47 previously or currently pregnant women. Most women had used condoms (87.2\%) and/or the combined oral contraceptive pill (74.4\%). Many did not know if intrauterine contraception (61.7\%) or contraceptive implants (43.7\%) were safe in DM.

\section{Discussion}

Despite being aware of the risks of DM in pregnancy, less than half of the women had sought preconception care, and many had poor knowledge of the most reliable contraceptive methods.
APPROXIMATELY ONE MILLION Australians have diabetes mellitus (DM), with estimates projected to rise to three million by $2025 .{ }^{1}$ In 2014,1 per 100 women giving birth in Australia had pre-existing DM. ${ }^{2}$ Women with diabetes have higher incidences of maternal, fetal and neonatal complications, including increased risk of congenital anomalies. ${ }^{3}$ Many of these risks can be reduced through tight glycaemic control before and during pregnancy. ${ }^{4}$ International ${ }^{5}$ and Australian guidelines ${ }^{6}$ recommend at least annual preconception counselling for all women of reproductive age who have DM. Despite this, most international studies and the one national audit report that only $30-40 \%$ of women with DM seek preconception care (PCC) and plan the timing of their pregnancies. ${ }^{7,8}$

One major barrier to pregnancy planning is access to, and use of, reliable contraception. Although nearly $70 \%$ of Australian women of child-bearing age report using contraception, ${ }^{9} 38.8 \%$ of women who had previously been pregnant reported a previous unintended pregnancy. ${ }^{10}$ On the basis of overseas data, approximately half of these unintended pregnancies result from inconsistent or incorrect use of contraception. ${ }^{11}$ Large studies show that unplanned pregnancies can be reduced through employment of less user-dependent methods of contraception, particularly the most reliable reversible methods - the long-acting reversible contraceptives (LARC), including contraceptive implants and intrauterine contraception (IUC). ${ }^{12}$ IUC methods available in Australia are the copper intrauterine devices and the levonorgestrel intrauterine system.
There are few studies exploring pregnancy planning and contraceptive use in Australian women with DM. ${ }^{13,14}$ To our knowledge, there are no Australian studies in women with DM exploring their use of contraception, nor their beliefs regarding the safety of different methods. Among a cohort of women with DM, the aim of this study was to explore women's understanding of the importance of pregnancy planning and the implications of poor glycaemic control on pregnancy outcomes, beliefs regarding the safety of different contraceptive methods in DM, sources of contraception information and contraception use.

\section{Methods}

We undertook a quantitative crosssectional questionnaire-based study in the Nepean Blue Mountains Local Health District (NBMLHD), a large tertiary referral centre. Between August 2013 and August 2015, we approached eligible women of reproductive age (16-49 years) with DM (type 1 or 2) to participate in the study. Women attending the diabetes service were invited at their scheduled clinic appointment or via mail/email to complete the survey. Women were sent a letter explaining the purpose of the survey, a plain language information flyer, a consent form and a paper copy of the survey. A reminder letter was sent three weeks later. The survey was promoted via local media and flyers displayed in the hospital.

The self-administered survey was available online or as a written postal survey. Survey questions were based on diabetes and pregnancy guidelines, ${ }^{7}$ the 
findings from a literature review and consultation with experts in pregnancy and diabetes. The survey (available online only) comprised 22 questions addressing demographic information (seven questions), thoughts and beliefs regarding pregnancy and contraception in DM (nine questions), current contraceptive practice (four questions) and previous pregnancies (two questions). Pilot testing was conducted with five women to optimise survey question clarity.

Participants were assigned a study number, and results were de-identified to maintain confidentiality. The data were analysed using SAS version 9.4. Any instances in which responses to a particular question were missing were noted (supplementary table, available online only), and the percentages were calculated using the number of women who answered that question as the denominator.

Chi-square tests were used to determine whether there were significant differences between categorical demographic characteristics and participants' responses to questionnaire questions. This was performed as a post-hoc analysis for four participant characteristics.

The study was approved by the NBMLHD Human Research Ethics Committee.

\section{Results}

A total of 107 of 215 women participated in the study, a response rate of $49.8 \%$. Several questions had missing responses ( $\leq 5$ per question). The mean age of participants was 26.7 years (range 16-49 years). The majority had type 1 DM (79.4\%) and were Australian-born (89.6\%). Other participant characteristics are shown in Table 1.

The responses to questions about pregnancy planning and contraception are documented in Table 2, including a comparison between answers of women with types 1 and 2 DM. Most women $(83.4 \%, \mathrm{n}=86)$ were aware of potential maternal and fetal complications associated with DM in pregnancy, while half $(50.5 \%, \mathrm{n}=52)$ were unsure of the need for medication changes prior to or during pregnancy. Contraceptive choice
Table 1. Characteristics of women who completed the survey $(n=107)$

n (\%)

\begin{tabular}{lr}
\hline Type of diabetes & $85(79.4)$ \\
\hline Type 1 & $17(15.9)$ \\
\hline Type 2 & $5(4.7)$ \\
\hline Not sure & $9(8.4)$ \\
\hline Duration of diabetes* & $25(23.4)$ \\
\hline$<1$ year & $16(14.9)$ \\
\hline $1-5$ years & $57(53.3)$ \\
\hline $6-10$ years & $51(47.7)$ \\
\hline$>10$ years & $39(36.4)$ \\
\hline Age group & $14(13.1)$ \\
\hline $16-24$ years & $3(2.8)$ \\
\hline $25-34$ years &
\end{tabular}

Country of birth

Australia

$95(89.6)$

\begin{tabular}{lr}
\hline Other $11(10.4)$ \\
\hline
\end{tabular}

Current relationship status

\begin{tabular}{lr}
\hline Single & $36(33.6)$ \\
\hline In a relationship & $29(27.1)$ \\
\hline Married or de facto & $39(36.4)$ \\
\hline Widowed & $1(0.9)$ \\
\hline Divorced/separated & $2(1.8)$
\end{tabular}

Highest level of education completed $(n=106)$

\begin{tabular}{lr}
\hline Primary school' & $10(9.4)$ \\
\hline High school $^{*}$ & $48(44.9)$ \\
\hline TAFE/university course & $48(44.8)$ \\
\hline Employment $^{\S}$ & $23(21.5)$ \\
\hline Studying full time & $10(9.4)$ \\
\hline Studying part time & $37(34.6)$ \\
\hline Working full time & $26(24.4)$ \\
\hline Working part time & $15(14.0)$ \\
\hline Unemployed & $10(9.3)$ \\
\hline Pension & $87(81.3)$ \\
\hline Sexually active & $20(18.7)$ \\
\hline Yes &
\end{tabular}

*Duration of diabetes was determined by current age minus age at diagnosis of diabetes

t'ncludes six women currently at high school

\#Includes 17 people who have attended high school to at least the level of Year 10

$\$ 14$ women reported both working and studying 
was regarded by most $(61.2 \% ; n=63)$ not to be significantly limited by DM. Over three quarters $(77.7 \%=80)$ believed combined oral contraceptive pills (COCPs) were safe in DM. However, $61.7 \%$ ( $=$ 66) were unsure of the safety of IUC in $\mathrm{DM}$, and $43.7 \%(\mathrm{n}=45)$ were unsure about the safety of contraceptive implants (Figure 1). Excluding women who were unsure of their diabetes type $(n=5)$, understanding of the complications and need for medication change was not different between those with types 1 and 2 DM. Women with a TAFE qualification or university degree were more likely to be aware of potential complications associated with DM in pregnancy than those whose highest level of education was secondary education: $93.7 \%$ of women, compared with $67.5 \%(P=0.0021)$. They were also more likely to know that they might need medication changes prior to pregnancy: $40 \%$ of women, compared with $25 \%(P=0.0181)$.

For $69.9 \%(n=71)$ of the participants, the general practitioner (GP) was the main source of information regarding contraception, followed by school (35.3\%, $\mathrm{n}=36)$ and family $(29.4 \%, \mathrm{n}=30)$. Endocrinologists $(15.7 \%, \mathrm{n}=16)$ and diabetes educators $(14.7 \%, \mathrm{n}=15)$ were uncommon sources.

Of the 87 women $(81.3 \%)$ who had ever been sexually active, 46 (54.8\%) reported a previous pregnancy and one reported a current pregnancy. Of these, 40 had at least one live birth (parity range 1-7), 16 had at least one miscarriage (range 1-4 with a total of 32 miscarriages) and four had one or more stillbirths (total of seven stillbirths). There were 12 terminations of pregnancy in 10 women.

Only $28.2 \%$ of women had ever had a specific discussion around planning for a pregnancy with their endocrinologist or GP. Even among sexually active women, approximately two-thirds $(65.5 \%, \mathrm{n}=57)$ had never had a specific discussion around planning for pregnancy. Of the 47 women who had been or were currently pregnant, preconception advice was reported by less than half $(46.8 \%, \mathrm{n}=22)$.

Of the 87 women who had ever been sexually active, condoms were the most commonly used form of contraception $(87.2 \%, \mathrm{n}=75)$, followed by COCPs $(74.4 \%, \mathrm{n}=64)$, contraceptive implants $(18.6 \% ; \mathrm{n}=16)$, contraceptive injections $(14.0 \%, \mathrm{n}=12)$, IUC $(4.6 \%, \mathrm{n}=4)$, female sterilisation $(2.3 \%, \mathrm{n}=2)$ and

Table 2. Participant responses to questions about pregnancy planning and contraception among reproductive age women $(n=103)$ with comparison of pattern of answers between women with type 1 and type 2 diabetes mellitus $(n=98)^{*}$

\begin{tabular}{|c|c|c|c|c|}
\hline & $\begin{array}{r}\text { Overall } \\
\text { n (\%) }\end{array}$ & $\begin{array}{r}\text { Type } 1 \text { diabetes } \\
\text { mellitus } \\
n(\%)\end{array}$ & $\begin{array}{r}\text { Type } 2 \text { diabetes } \\
\text { mellitus } \\
n(\%)\end{array}$ & $P$ value \\
\hline Yes & $29(28.2)$ & $22(27.2)$ & $7(41.2)$ & 0.25 \\
\hline \multicolumn{5}{|c|}{$\begin{array}{l}\text { Do you know if you need to stop or change medication before or } \\
\text { during pregnancy? }\end{array}$} \\
\hline Yes & 35 (34.0) & 27 (33.3) & $7(41.2)$ & 0.43 \\
\hline No & $16(15.5)$ & 15 (18.5) & $1(5.9)$ & \\
\hline Yes & $86(83.5)$ & $67(82.7)$ & $16(94.1)$ & $0.0695^{\dagger}$ \\
\hline No & $3(2.9)$ & $1(1.2)$ & $1(5.9)$ & \\
\hline Not sure & 14 (13.6) & $13(16.1)$ & $0(0)$ & \\
\hline \multicolumn{5}{|c|}{$\begin{array}{l}\text { Do you think women with diabetes have more limited } \\
\text { contraceptive choices? }\end{array}$} \\
\hline Not/minimal limits & $63(61.2)$ & $53(65.4)$ & $7(41.2)$ & $0.0963^{+}$ \\
\hline Don't know & $34(33.0)$ & 25 (30.9) & $8(47.1)$ & \\
\hline Quite/very limited & $6(5.8)$ & $3(3.7)$ & $2(11.8)$ & \\
\hline
\end{tabular}


male sterilisation $(2.3 \%, \mathrm{n}=2)$. Sixteen per cent $(n=14)$ of sexually active women had never used any form of contraception. Contraception use in the last 12 months is documented in Table 3. Almost a quarter of the women $(24.7 \%, \mathrm{n}=21)$ reported no use of contraception, and only three (3.5\%) were using one of the LARC methods.

\section{Discussion}

This study found that despite knowledge of the adverse effects of DM on pregnancy, Australian women with DM report low rates of preconception counselling and care. Optimal pregnancy planning requires use of reliable contraception, but women in this study expressed uncertainty about the most reliable methods - IUC and implants. Of concern, many of the sexually active women in the study were not using any method or were not using the most reliable methods.

Reported rates of preconception counselling among all women with DM were exceptionally low at $28.2 \%$ in our study. In a 2015 National Diabetes Services Scheme (NDSS) survey of 967 Australian women with DM, ${ }^{13}$ $70 \%$ reported discussion with a health professional regarding pregnancy, although this was markedly lower in women with type $2 \mathrm{DM}$ (44\%). In that survey, the majority of pregnancy-related conversations with a health professional were initiated by the patient (59\%). A number of factors may have contributed to the differences in rates between these two studies, including a low response rate for the NDSS survey (16\%), potential response bias in that women who had received preconception counselling or who had better knowledge of pre-pregnancy planning may have responded to the survey, and the age and education level of the respondents. Our sample was younger (mean age of 26.7 years in our study, compared with 34 years for NDSS), less educated and of lower socioeconomic status than the NDSS patient population, which likely has an impact on the understanding and experience of DM-related pregnancy risks.
Our findings are also significantly worse than those reported in France ${ }^{15}$ and the UK, ${ }^{16}$ where rates of preconception counselling occurred for $85 \%$ of women with type $1 \mathrm{DM}$ and $67 \%$ of women with type $2 \mathrm{DM}$, but similar to those in a US study of 80 women with type $1 \mathrm{DM}$, in which $65 \%$ indicated no knowledge of PCC. ${ }^{17}$ Although not seen in our study, which had low numbers of women with type $2 \mathrm{DM}$, other studies show that women with type $2 \mathrm{DM}$ are at

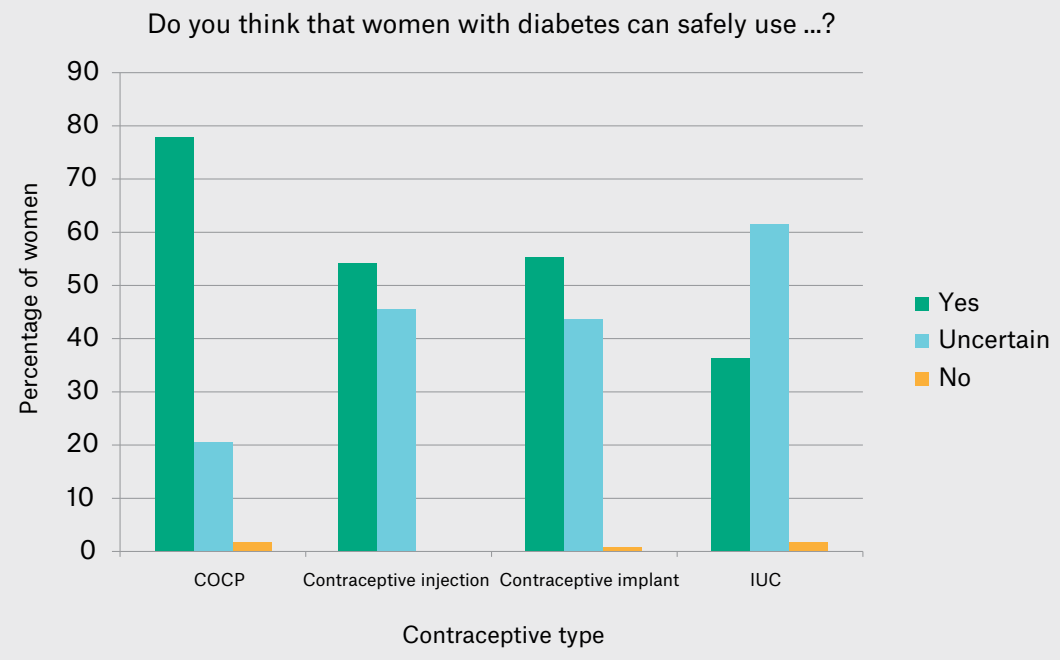

Figure 1. Contraceptive knowledge of the safety of different methods in women with diabetes COCP, combined oral contraceptive pill; IUC, intrauterine contraception

Table 3. Main contraception used in the last 12 months among ever sexually active women $(n=85)$

\begin{tabular}{lr}
\hline Contraceptive method & Number (\%) \\
\hline Nil & $21(24.7)$ \\
\hline Condoms & $18(21.2)$ \\
\hline Intrauterine contraception & $17(20.0)$ \\
\hline Injection & $0(0)$ \\
\hline Implant & $3(3.5)$ \\
\hline Female sterilisation & $6(7.0)$ \\
\hline Male sterilisation & $1(1.2)$ \\
\hline Not applicable (one specified no intercourse) & $2(2.4)$ \\
\hline Other (one breastfeeding, one withdrawal) & $2(2.4)$ \\
\hline Multiple methods: condoms plus COCP & $2(2.4)$ \\
\hline Multiple methods: nil \pm condoms and pregnant & $6(7.0)$ \\
\hline Multiple methods: other & $3(3.5)$ \\
\hline
\end{tabular}


particular risk of being overlooked for preconception counselling. These women more often receive non-specialist care, have associated obesity and metabolic syndrome (which confer high risks for pregnancy) and are at risk of continuing potentially teratogenic medications (eg statins). ${ }^{18}$ This is particularly an issue for Aboriginal and Torres Strait Islander mothers, who have a 10 times greater rate of type $2 \mathrm{DM}$ compared with the general maternal population, and higher rates of adverse perinatal outcomes. ${ }^{19}$

Consistent with previous Australian studies, ${ }^{9,20}$ the forms of contraception most commonly used by women of reproductive age were condoms and COCPs. Reported use of the most reliable methods - the LARC methods - was higher for implants but lower for IUCs when compared with national rates, ${ }^{9}$ and lower than international rates for both implants and IUCs. ${ }^{21}$ One study has shown that with a clear 'LARC first' counselling strategy, over twothirds of young women under the age of 25 years will choose an IUC method or implant. ${ }^{12}$ It is particularly important that LARC is considered a first-line option in women with DM, as the risks associated with unplanned pregnancy are high. Furthermore, even in women with nephropathy, retinopathy, neuropathy or other vascular disease, the implants and IUC are not contraindicated, unlike COCPs. ${ }^{22}$ However, misconceptions regarding safety and side effects in both patients and providers, lack of training in LARC insertion and poor awareness of LARC benefits contribute to low uptake in Australia. ${ }^{23,24}$

The main source of contraceptive advice identified in our study was GPs, while discussions with endocrinologists or diabetes educators were uncommon. Therefore, GPs have a crucial role to play in alleviating uncertainty about the LARC methods and in contraception provision, while endocrinologists should consider knowledge of contraceptive options for women with DM part of their remit.

The main strength of this study is that it is the first Australian study to provide data on preconception counselling, contraceptive use and knowledge regarding diabetes and pregnancy in women of reproductive age with DM in Western Sydney. Limitations of the study include the small sample size and predominantly young, Australian-born population of lower socioeconomic background, which may limit generalisability of results. The questionnaire format of the study may have led to recall bias, in addition to the potential for fabricated answers because of fear of embarrassment, although questionnaire responses were coded and thus de-identified to minimise the risk of fabricated answers. Results are descriptive and adjustments have not been made for potential confounders in the limited chisquare testing performed.

In conclusion, women of childbearing age with DM in the NBMLHD understand that there are pregnancy-related risks in DM but have limited uptake of preconception planning. Although LARC methods are recommended in clinical guidelines, women with DM have substantial uncertainty regarding their safety in DM. Use of contraceptive implants is higher than national averages, but reported IUC use is lower. Health professionals, particularly GPs and endocrinologists, need to be proactive in initiating conversations around pregnancy planning and revisiting the topic yearly, including providing advice on safe, effective forms of contraception to avoid unintended pregnancy. Employment of the 'One Key Question' initiative, asking 'Would you like to become pregnant in the next year?', is recommended. ${ }^{25}$ However, even when the response is 'no', it is prudent to discuss both preconception planning and contraception, as a high proportion of pregnancies are unplanned.

\section{Authors}

Emily J Hibbert MBBS(Hons), MClinEd, FRACP, Associate Professor in Medicine (Endocrinology), Nepean Clinical School, Faculty of Medicine and Health, University of Sydney, NSW; Head of Dept Endocrinology and Endocrinologist, Nepean Hospital, Penrith, NSW.emily.hibbert@sydney.edu.au

Santhi Chalasani MBBS(Hons), FRACP, MPhil (Medicine), Endocrinologist, Sydney, NSW

Pinar Kozan MBBS, MSc, FRACP, Endocrinologist, Orange, NSW

Rickie Myszka, Clinical Nurse Consultant in Diabetes, Diabetes Service, Nepean Hospital, Penrith, NSW
Kris EJ Park FRACP, MBBS, PhD, Senior Staff Endocrinologist, Nepean Blue Mountains Local Health District, NSW

Kirsten I Black MBBS, MMed, FRANZCOG, DDu, $\mathrm{PhD}, \mathrm{MFSRH}$, Associate Professor, Discipline of Obstetrics, Gynaecology and Neonatology, Central Clinical School, Faculty of Medicine and Health, University of Sydney, NSW

Competing interests: Kirsten Black attended one international advisory board meeting for Bayer Health who make one of the intrauterine contraceptive methods. There are no other competing interests. Funding: Postage of study questionnaires was funded by the Department of Endocrinology, Nepean Hospital. Provenance and peer review: Not commissioned, externally peer reviewed.

\section{References}

1. Baker IDI Heart and Diabetes Institute. Diabetes: The silent pandemic and its impact on Australia. Baulkham Hills, NSW: Novo Nordisk, 2012.

2. Australian Institute of Health and Welfare. Australia's mothers and babies 2014 - In brief. Canberra: AlHW, 2016.

3. Shand AW, Bell JC, McElduff A, Morris J Roberts CL. Outcomes of pregnancies in women with pre-gestational diabetes mellitus and gestational diabetes mellitus; A population-based study in New South Wales, Australia, 1998-2002. Diabet Med 2008;25(6):708-15. doi: 10.1111/j.14645491.2008.02431.x

4. Owens LA, Egan AM, Carmody L, Dunne F. Ten years of optimizing outcomes for women with type 1 and type 2 diabetes in pregnancy - The Atlantic DIP experience. J Clin Endocrinol Metab 2016:101(4):1598-605. doi: 10.1210/jc.2015-3817.

5. American Diabetes Association. Diabetes in pregnancy guidelines 2016. USA: American Diabetes Association, 2016.

6. Mclntyre HD, Flack JR, National Diabetes in Pregnancy Advisory Committee. Consensus statement on diabetes control in preparation for pregnancy. Med J Aust 2004;181(6):326.

7. McElduff A, Cheung NW, Mclntyre HD, et al. The Australasian Diabetes in Pregnancy Society consensus guidelines for the management of type 1 and type 2 diabetes in relation to pregnancy. Med J Aust 2005;183(7):373-77.

8. Dunne FP, Brydon P, Smith T, Essex M, Nicholson H, Dunn J. Pre-conception diabetes care in insulin-dependent diabetes mellitus. QJM 1999;92(3):175-76.

9. Richters J, Fitzadam S, Yeung A, et al. Contraceptive practices among women: The second Australian study of health and relationships. Contraception 2016;94(5):548-55. doi: 10.1016/j.contraception.2016.06.016.

10. Rowe H, Holton S, Kirkman M, et al. Prevalence and distribution of unintended pregnancy: The Understanding Fertility Management in Australia National Survey. Aust N Z J Public Health 2016;40(2):104-09. doi: 10.1111/1753-6405.12461.

11. Singh S, Sedgh G, Hussain R. Unintended pregnancy: Worldwide levels, trends, and outcomes. Stud Fam Plann 2010;41(4):241-50.

12. Winner B, Peipert JF, Zhao Q, et al. Effectiveness of long-acting reversible contraception. N Eng J Med 2012;366(21):1998-2007. doi: 10.1056/ NEJMoa1110855.

13. National Diabetes Services Scheme. Contraception, pregnancy and women's health: A survey of women with diabetes. Canberra: Diabetes Australia, 2015. 
14. Macintosh MC, Fleming KM, Bailey JA, et al. Perinatal mortality and congenital anomalies in babies of women with type 1 or type 2 diabetes in England, Wales, and Northern Ireland:

Population based study. BMJ 2006;333(7560):177. doi: 10.1136/bmj.38856.692986.AE.

15. Diabetes and Pregnancy Group. Knowledge about preconception care in French women with type 1 diabetes. Diabetes Metab 2005:31(5):443-47.

16. Shawe J, Smith P, Stephenson J. Use of contraception by women with type 1 or type 2 diabetes mellitus: 'It's funny that nobody really spoke to me about it'. Eur J Contracept Reprod Health Care 2011;16(5):350-58. doi: 10.3109/13625187.2011.597896.

17. Charron-Prochownik D, Sereika SM, Wang SL, et al. Reproductive health and preconception counseling awareness in adolescents with diabetes: What they don't know can hurt them. Diabetes Educ 2006;32(2):235-42. doi: 10.1177/0145721706286895.

18. Reddy SM, Ramachandran A, Cabral H, Kazis L. Provision of family planning to women with cardiovascular risk factors. J Am Board Fam Med 2015;28(1):105-14. doi: 10.3122/ jabfm.2015.01.140016.

19. Australian Institute of Health and Welfare. Diabetes in pregnancy: Its impact on Australian women and their babies. Canberra: AIHW, 2010.

20. Mazza D, Harrison C, Taft A, et al. Current contraceptive management in Australian general practice: An analysis of BEACH data. Med J Aust 2012;197(2):110-14.

21. United Nations, Department of Economic and Social Affairs, Population Division. Trends in Contraceptive Use Worldwide 2015. New York: United Nations, 2015. Available at http://www.un.org/en/development/ desa/population/publications/pdf/family/ trendsContraceptiveUse2015Report.pdf [Accessed 18 October 2018].

22. Faculty of Sexual and Reproductive Healthcare of the Royal College of Obstetricians \& Gynaecologists (FSRH). The UK medical eligibility criteria for contraceptive use. London: FSRH, 2016. Available at www.fsrh.org/ukmec [Accessed 11 June 2018].

23. Black KI, Bateson D, Harvey C. Australian women need increased access to long-acting reversible contraception. Med J Aust 2013;199(5):317-18.

24. Holton S, Rowe H, Kirkman M, et al. Longacting reversible contraception: Findings from the Understanding Fertility Management in Contemporary Australia survey. Eur J Contracept Reprod Health Care 2016;21(2):116-31. doi: 10.3109/13625187.2015.1052394.

25. Oregon Health Authority. Effective contraceptive use among women at risk of unintended pregnancy guidance document. Oregon: Oregon Health Authority, 2014. Available at www.oregon.gov/oha/HPA/ ANALYTICS/CCOData/Effective\%20 Contraceptive\%20Use\%20Guidance\%20 Document.pdf [Accessed 23 June 2018]. 


\section{Supplementary table. Number of responses and number of missing values for each question in contraception} questionnaire

Question
No. of participants who answered
No. of participants eligible to answer
No. of missing

values

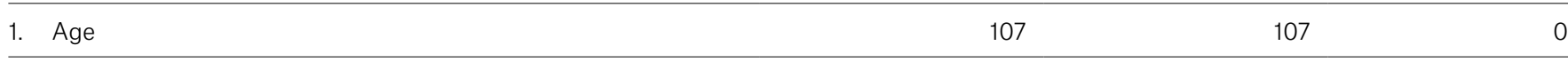

2. Country of birth 106

3. Relationship status

4. Age of diagnosis of diabetes mellitus

107

107

5. Type of diabetes mellitus

107

6. Level of education

7. Current employment status

106

107

8. Sources of knowledge regarding contraception

9. Specific discussion around pregnancy with general practitioner/endocrinologist

102

103

103

103

103

107

4 diabetes mellitus?

13. Do you believe that women with diabetes mellitus can safely take the oral contraceptive pill?

14. Do you think that women with diabetes mellitus can safely use a contraceptive implant?

15. Do you think that women with diabetes mellitus can safely use the contraceptive injection?

16. Do you think that women with diabetes mellitus can safely use an intrauterine device?

17. Have you ever been sexually active?

18. What forms of contraception have you ever used?

19. What has been your main form of contraception in the past 12 months?

20. What has been your main form of contraception in the past month?

21. Have you ever been pregnant?

103

107

107

107

86

85

84

84

46

47 you had each of the following? (Live birth, stillbirth, miscarriage, termination of pregnancy, ectopic pregnancy) 